\title{
Rheological properties of low-density polyethylene filled with hydrophobic Co(Ni)-Al layered double hydroxides
}

\author{
Silvia Jaerger ${ }^{1}$, Andreas Leuteritz ${ }^{2}$, Rilton Alves de Freitas ${ }^{1}$ and Fernando Wypych ${ }^{1 *}$ (i) \\ ${ }^{1}$ Departamento de Química - DQUI, Universidade Federal do Paraná - UFPR, Curitiba, PR, Brasil \\ ${ }^{2}$ Leibniz-Institut für Polymerforschung Dresden e.V. - IPF, Dresden, Germany \\ *wypych@ufpr.br
}

\begin{abstract}
Cobalt/aluminum and nickel/aluminum layered double hydroxide (LDH - $\mathrm{M}^{+2}$ :Al molar ratio of 3:1) were intercalated with dodecylsulphate (DDS), laurate (LAU), stearate (STE) and palmitate (PAL) and used as filler in low-density polyethylene (LDPE) in percentages between 0.2 and $7.0 \mathrm{wt} \%$. After injection molding, the samples were submitted to morphological characterization by scanning electron microscopy (SEM), analysis of thermal behavior by differential scanning calorimetry (DSC) and investigation of rheological properties. All Co/Al-LDPE samples showed the formation of a high temperature polymer crystal domain, induced by the LDH filler. The rheological properties indicated in general a reduction of shear modulus due to incompatibility between some regions of LDH and LDPE, which promoted phase separation. However, interaction with the LDH surface indicated higher affinity of the Ni/Al-LDH for the LDPE compared to $\mathrm{Co} / \mathrm{Al}-\mathrm{LDH}$, forming permanent networks.
\end{abstract}

Keywords: layered double hydroxide, low-density polyethylene, nanocomposites, rheological properties.

How to cite: Jaerger, S., Leuteritz, A., Freitas, R. A., \& Wypych, F. (2019). Rheological properties of low-density polyethylene filled with hydrophobic Co(Ni)-Al layered double hydroxides. Polímeros: Ciência e Tecnologa, 29(1), e2019007. https://doi.org/10.1590/0104-1428.09717

\section{Introduction}

Low-density polyethylene (LDPE) is widely used in the production of packaging films, but its use can be expanded by improving its properties. Polymeric composites using natural and synthetic layered fillers can be interesting alternatives to improve some polymer properties, especially mechanical, gas barrier, flame retardancy, etc ${ }^{[1-5]}$.

Polymer nanocomposites (PNC) are materials in which the matrix is a polymer and the filler has at least one dimension of nanometer magnitude, normally smaller than $100 \mathrm{~nm}^{[6]}$. Layered compounds are composed of two dimensional nanosized layers, which are stacked along the basal axis, being ideal for use as fillers in $\mathrm{PNC}^{[7]}$. Normally, hydrophilic layered compounds can become hydrophobic after the intercalation of specific organic anionic species. The most common are the carboxylates and sulphonates ${ }^{[8,9]}$. The majority of studies devoted to PNC use clay minerals of the 2:1 groups cation exchangers, but they present many disadvantages, which can be overcome by the use of synthetic layered compounds ${ }^{[3-5,10,11]}$.

Layered double hydroxide (LDH) having the general formula $\left[\mathrm{M}^{+2}{ }_{1-\mathrm{x}} \mathrm{M}^{+3}{ }_{\mathrm{x}}(\mathrm{OH})_{2}\right]^{\mathrm{x}+}\left[\mathrm{A}^{\mathrm{m}-}\right]_{\mathrm{x} / \mathrm{m}} \cdot \mathrm{yH}_{2} \mathrm{O}$, where $\mathrm{M}^{2+}$ and $\mathrm{M}^{3+}$ represent di and trivalent metals, respectively occupying octahedral sites coordinated by hydroxyl groups and $\mathrm{A}^{\mathrm{m}-}\left(\mathrm{H}_{2} \mathrm{O}\right)$ an intercalated hydrated anion, have been recently proposed as alternative materials for use as fillers in the formulation of $\mathrm{PNC}^{[5,10,11]}$. LDHs can be obtained with variable chemical composition, and to overcome the hydrophilic properties of

$\mathrm{LDH}$, long carbon chain anionic species are intercalated, such as those derived from ethylene diaminetetraacetic acid ${ }^{[12]}$, aromatic acid ${ }^{[13]}$, dihydroxybenzoic acid ${ }^{[14]}$, chromotropic $\operatorname{acid}^{[15]}$, dodecylsulphonic acid ${ }^{[16]}$, stearic acid ${ }^{[17]}$, oleic $\operatorname{acid}^{[18]}$, and dodecylbenzenesulphonic acid ${ }^{[19]}$.One extra advantage of using LDH is the possibility to impart color to the polymeric matrix, where the intercalated anions or layers of structural cations can be colored ${ }^{[20,21]}$. This will avoid the use pigments or dyes as polymer colorants.

To date, very few studies have been published described the rheology of LDH-polymer (PE) interactions ${ }^{[22-32]}$. For example, Costa et al. ${ }^{[22,23]}$ studied the rheological properties of $\mathrm{Mg} / \mathrm{Al}$ based layered double hydroxide-polyethylene and polyethylene grafted with maleic anhydride and demonstrated only strong interactions between the LDH with grafted maleic anhydride matrix. The authors also observed some structural aggregation, ruptured by shearing but reformed after resting.

In our previous study ${ }^{[33]}$, we described the preparation of a LDPE nanocomposite containing organo-modified $\mathrm{Ni} / \mathrm{Al}$ and $\mathrm{Co} / \mathrm{Al}-\mathrm{LDH}$ using melt extrusion. The mechanical properties, transmission electron micrographs and differential scanning calorimetric results showed that the addition of these LDHs had a small influence on the polymer properties, even in the case of good dispersions and exfoliation of the LDH layered crystals. 
To date, very few studies have been published described the rheology of LDH-polymer (PE) interactions ${ }^{[22-32]}$. For example, Costa et al. ${ }^{[22,23]}$ studied the rheological properties of $\mathrm{Mg} / \mathrm{Al}$ based layered double hydroxide-polyethylene and polyethylene grafted with maleic anhydride and demonstrated only strong interactions between the LDH with grafted maleic anhydride matrix. The authors also observed some structural aggregation, ruptured by shearing but reformed after resting.

In the present study, morphological, thermal and rheological experiments were conducted on LDPE nanocomposites containing hydrophobic Ni/Al-LDH and $\mathrm{Co} / \mathrm{Al}-\mathrm{LDH}$ as filler. Rheological analyses investigate the linear viscoelastic properties of the nanocomposites and proved to be a good technique to understand more clearly the nature of particle dispersion in PNC. Under the linear viscoelastic regime, rheological behavior is very sensitive to any change in microstructure of composites when the shearing is carried out under very low shear rates, and it can provide information that can explain the clay particle state dispersion and possible particle-particle and particlepolymer interactions. These possibilities for improvement will be discussed in this manuscript.

\section{Materials and Methods}

\subsection{Materials}

LDPE, PB608 (MFI $30 \mathrm{~g} / 10 \mathrm{~min}$ and density $0.915 \mathrm{~g} / \mathrm{cm}^{3}$ ) was a resin free of additives and was kindly donated by Braskem (Brazil). Hydrophilic Ni/Al-LDH and Co/Al-LDH $\left(\mathrm{M}^{+2}: \mathrm{M}^{+3}\right.$ molar ratio of 3:1), intercalated with the anions carbonate, chloride and nitrate, were prepared by hydrolysis and the hydrophobic materials, intercalated with the anions laurate (LAU), palmitate (PAL), dodecylsulphate (DDS) and stearate (STE), were prepared by ion exchange method and characterized by different techniques, as describe in the previous article ${ }^{[33]}$. Briefly, first the carbonate derivatives were prepared by urea hydrolysis, serving as matrix for the preparation of the chloride derivative, obtained by treating the sample in an acetate buffer solution containing $\mathrm{NaCl}$. Next, chloride anions were replaced by the specific organic anions by exchange reactions.

\subsection{Instrumental techniques}

The LDH samples were characterized and were added to LDPE, using different percentages in relation to the LDPE mass $(0.2,0.5,2.0,5 \text { and } 7 \mathrm{wt} \%)^{[33]}$. The mixture was fed into a HAAKE MiniLab II micro compounder and then specimens were prepared of each composition by melting the LDPE/filler mixtures at $160 \mathrm{bar}, 130^{\circ} \mathrm{C}$ for 5 minutes. The material was then injected at 320 bar into a mold cavity (at $40{ }^{\circ} \mathrm{C}$ ) to produce ASTM D638 samples (type IV) in a HAAKE MiniJet II injector. For statistical purposes, ten specimens were evaluated for each composition and average values are presented, excluding outliers.

The samples for the scanning electron microscopy (SEM) measurements were obtained by dipping the composites in liquid $\mathrm{N}_{2}$, followed by fracturing and placement on aluminum stubs with conductive glue for gold sputtering.
The images were recorded with a Tescan VEGA3 LMU microscope at $10 \mathrm{kV}$.

Differential scanning calorimetry (DSC) analysis of the nanocomposites was performed with a Netzsch DSC 200 calorimeter under nitrogen atmosphere using the following running cycle: heating from room temperature to $180^{\circ} \mathrm{C}\left(\right.$ at $\left.10^{\circ} \mathrm{C} \cdot \mathrm{min}^{-1}\right)$, stabilization for $5 \mathrm{~min}$ at $150^{\circ} \mathrm{C}$, cooling to $-80^{\circ} \mathrm{C}$ (at $10^{\circ} \mathrm{C} \cdot \mathrm{min}^{-1}$ ), and heating to $150^{\circ} \mathrm{C}$ $\left(\right.$ at $10^{\circ} \mathrm{C} \cdot \mathrm{min}^{-1}$ ). After eliminating the thermal history of the PNC, only the first cooling and second heating curves were recorded.

Rheological studies were performed with the aid of an ARES rheometer from Rheometrics Scientific, USA, using parallel plates. The torque transducers varied from $0.02-2000 \mathrm{~g} \cdot \mathrm{cm}^{-1}$ and the temperature of the sample was controlled in a closed chamber under nitrogen atmosphere. The samples were pressed and molded with diameter of $25 \mathrm{~mm}$ and thickness of $1.5 \mathrm{~mm}$. The dynamic oscillatory shear experiment occurred at $190^{\circ} \mathrm{C}$ with a frequency sweep of $0.063-100$ rad.s $\mathrm{s}^{-1}$, where the amplitude was maintained at $10 \%$, which is the range for viscoelastic polymers.

\section{Results and Discussions}

In order to gain a better understanding of the LDH-LDPE nanocomposites' behavior, SEM (Figure 1) and DSC (Figure 2) measurements were performed with all the Ni/Al and $\mathrm{Co} / \mathrm{Al}$ samples. After, a complete rheological description of the interactions between LDH-LDPE will be presented (Figure 3-8 and Appendix A).

The SEM images (Figure 1) are shown with lower magnification to have an idea of the whole sample surface and with higher magnification to note the surface details. In the SEM images of the samples of Ni/Al-LDPE (Figure 1a-d), poor dispersion of the filler is observed in micrometric scale, with segregation of agglomerates consisting basically of LDH (see white particles in Figure 1a, c). These aggregates were sometimes detached from the polymeric matrix during cryogenic fracture, as observed in Figure 1b, d, leaving large depressions (layered particles pull-out).

The sample Ni/Al-STE (Figure 1b) presented the best dispersion, since no agglomerations were detected, even in the low magnification image, suggesting low phase separation of LDH Ni/Al-STE and LDPE.

In the SEM images of the samples of Co/Al-LDPE (Figure 1e-h), relatively homogeneous phases were observed in micrometric scale, with the segregation of some particles rich in LDH but embedded in the LDPE matrix, in which LDH was also dispersed. This was more frequently observed in the cases of Co/Al-LAU (Figure 1g), Co/Al-PAL (Figure 1h) and Co/Al-STE (Figure 1f). In the Co/Al-STE phase, the XRD patterns also indicated the delamination/exfoliation of the layered crystals in the polymeric matrix ${ }^{[33]}$.

Since these layered particles were particularly evident in the Co/Al-LDPE samples, we suppose this can be attributed to those observed in high melting/crystallization peaks by DSC (Figure 2a, b), also exclusive for the same samples.

As can be observed for Co/Al-STE (Figure 2a), the first cooling presented two exothermic peaks, at 89 and $109^{\circ} \mathrm{C}$. 
The first is attributed to the crystallization of $\mathrm{LDPE}^{[31]}$ and the second is related to the formation of crystalline domains at high temperature, with the influence of the filler, which acts as a nucleating agent ${ }^{[32]}$. This high temperature phase occurs due to the effective interaction between polymeric chains and the LDH particles surface, where different crystal sizes or even different polymorphic phases of HDPE are obtained, due to different chain conformations.

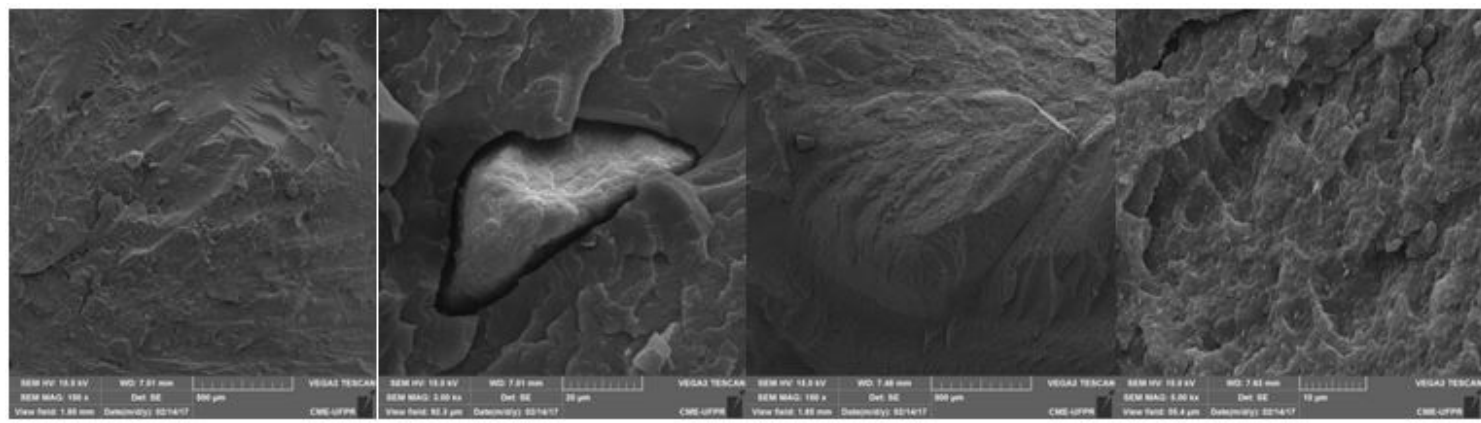

(a)

(b)

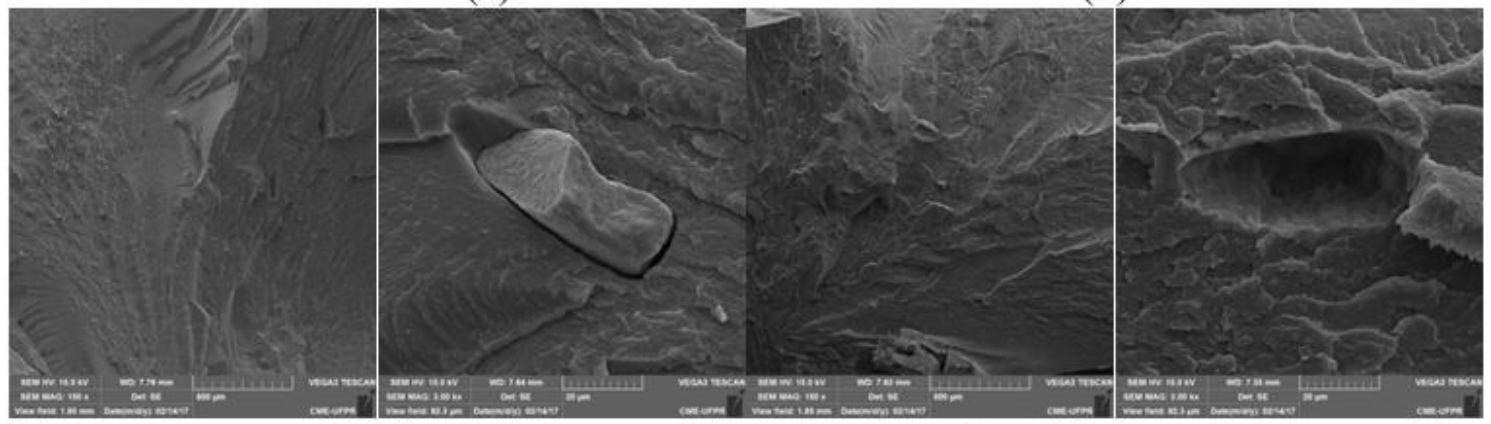

(c)

(d)



(e)

(f)

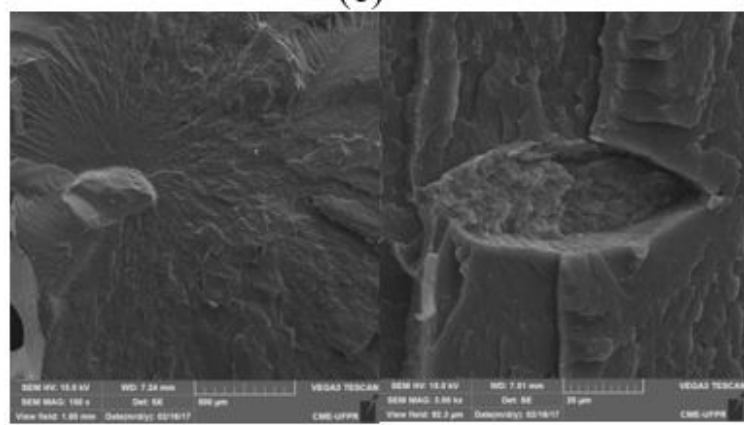

(g)

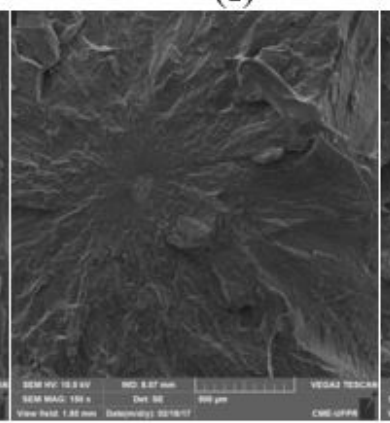

(h)

Figure 1. SEM images of cryogenic fracture for the LDPE nanocomposites containing 7\% of the fillers: Ni/Al-DDS (a), Ni/Al-STE (b), Ni/Al-LAU (c), Ni/Al-PAL (d), Co/Al-DDS (e), Co/Al-STE (f), Co/Al-LAU (g), and Co/Al-PAL (h). The LDH crystals can be seen as white plates. 

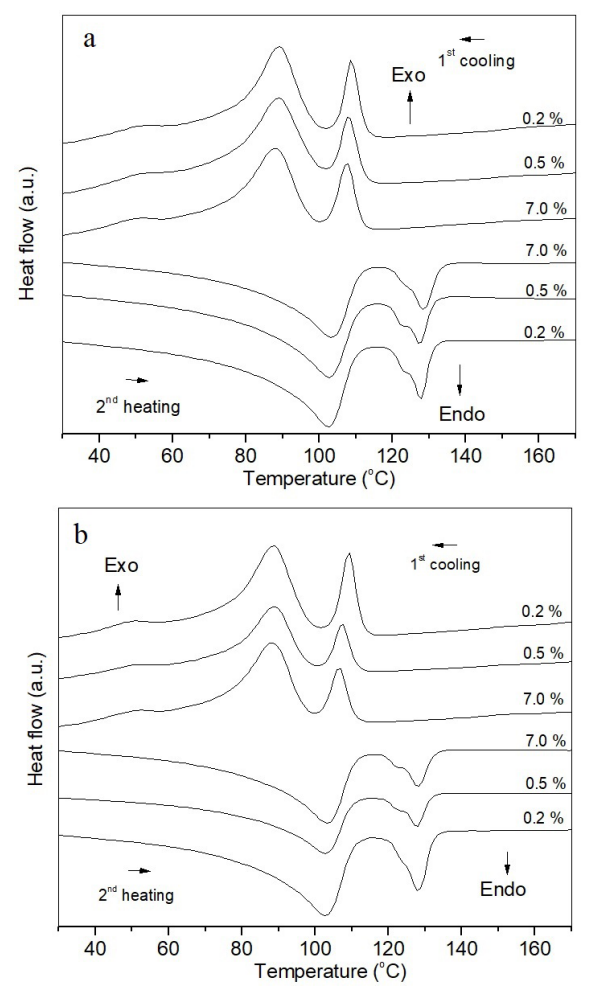

Figure 2. DSC curves of the Co/Al-STE (a) and Co/Al-PAL (b) LDPE nanocomposites containing $0.2,0.5$ and $7 \%$ of the fillers.
In the second melting, three endothermic events were observed, at 102,123 and $128^{\circ} \mathrm{C}$. The first is attributed to the melting of $\mathrm{LDPE}^{[31]}$ and the second and third to the melting of the phases obtained at high temperature, induced by the LDH filler ${ }^{[11]}$. In the phase of Co/Al-PAL (Figure 2b), similar behavior was observed with the same position of the melting/crystallization temperatures (Table 1).

One important aspect to be observed is that the proportion between the regular phase of LDPE and the high temperature phase was almost constant with rising filler content. This can be seen when the melting and crystallization enthalpies of both phases are compared (Table 1). Similar high temperature/ low temperature phase ratios were observed for the samples $\mathrm{Co} / \mathrm{Al}-\mathrm{PAL}$ and $\mathrm{Co} / \mathrm{Al}-\mathrm{STE}$ for crystallization and melting.

Another observation is the reduction of the enthalpies compared to the neat LDPE and with increasing content of both fillers, indicating reduction of LDPE chain mobility, hindering formation of polymer crystal domains. This can be attributed to the good interaction between the two phases. In fact, both evaluated samples did not show any diffraction peak in the X-ray diffraction pattern, even with $4 \%$ filler, indicating delamination/exfoliation (data not shown). The DSC splitting of the crystallization/melting peaks were not observed for the samples containing Ni/Al-LDPE, independent of the intercalated organic anion, as reported previously ${ }^{[33]}$.

The LDPE nanocomposites filled with different proportions of hydrophobic $\mathrm{LDH}(\mathrm{Ni} / \mathrm{Al}-\mathrm{LDH}$ and $\mathrm{Co} / \mathrm{Al}-\mathrm{LDH}$
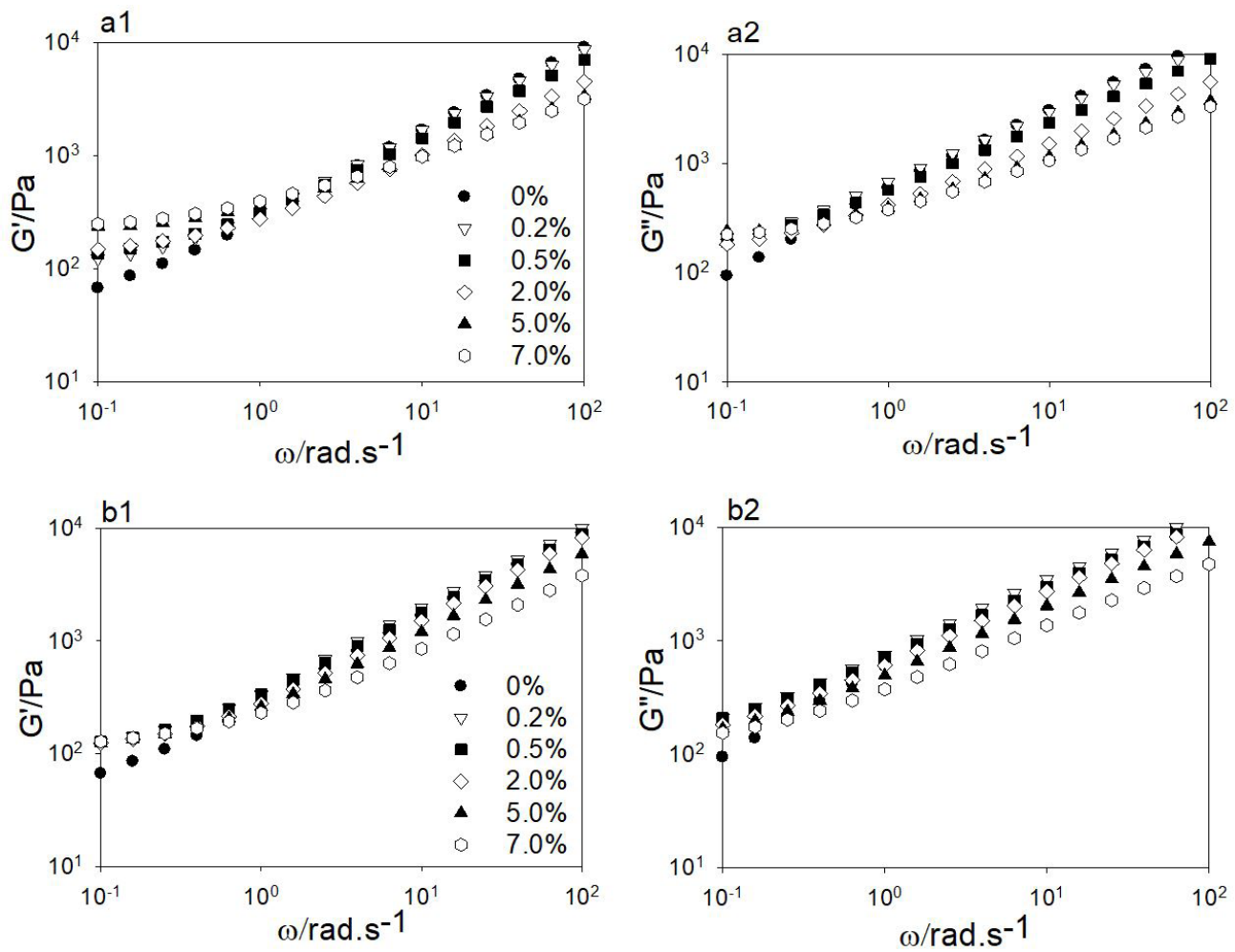

Figure 3. Frequency dependence of the shear modulus G' and G" of Ni/Al-LAU (a1 and a2) and Ni/Al-STE (b1 and b2) $(0.2,0.5,2.0,5.0$ and $7 \mathrm{wt} \%)$ in LDPE at $190{ }^{\circ} \mathrm{C}$. 
intercalated with the anions DDS, LAU, PAL or STE), were also evaluated by shear modulus frequency dependence using rheological analysis at $190^{\circ} \mathrm{C}$. In the first part of the results and discussion section, $\mathrm{Ni} / \mathrm{Al}-\mathrm{LDH}$ filler will be presented while in the second part, the focus will be on Co/Al-LDH and LDPE mixtures, for comparative purposes. The elastic modulus $\left(G^{\prime}\right)$ and viscous modulus $\left(G^{\prime \prime}\right)$ of Ni/Al-LAU and $\mathrm{Ni} / \mathrm{Al}$-STE are presented in Figure $3 \mathrm{a}$ and $3 \mathrm{~b}$, respectively. The shear modulus for Ni/Al-LDH DDS and PAL are presented in the Appendix A (Figure A1).

At low LDH concentration, no significant effect on LDPE shear moduli was observed. However, with the increase of concentration ( $\geq 2 \mathrm{wt} \%$ ) for all $\mathrm{Ni} / \mathrm{Al}-\mathrm{LDH}$ in LDPE, a reduction of G' and G' values was observed compared to neat LDPE (without any filler). This reduction of G' and G" was not expected, and the shear moduli reduction at higher frequencies can be attributed to a phase separation processes. Such hypothesis will be investigated below.

To improve the comparison between all the fillers and concentrations with LDPE, master curves were constructed, using a vertical shift factor $\left(\mathrm{a}_{\mathrm{v}}\right)$ obtained at high frequency range $\left(\sim 100\right.$ rad. $\left.\mathrm{s}^{-1}\right)$. The shift factor was used on both $\mathrm{G}^{\prime}$ and G" raw values (Figure 4). The $\mathrm{a}_{\mathrm{v}}$ values were obtained by the ratio of LDPE with the shear modulus of LDPE-LDH mixtures. This high frequency was chosen to calculate $a_{v}$
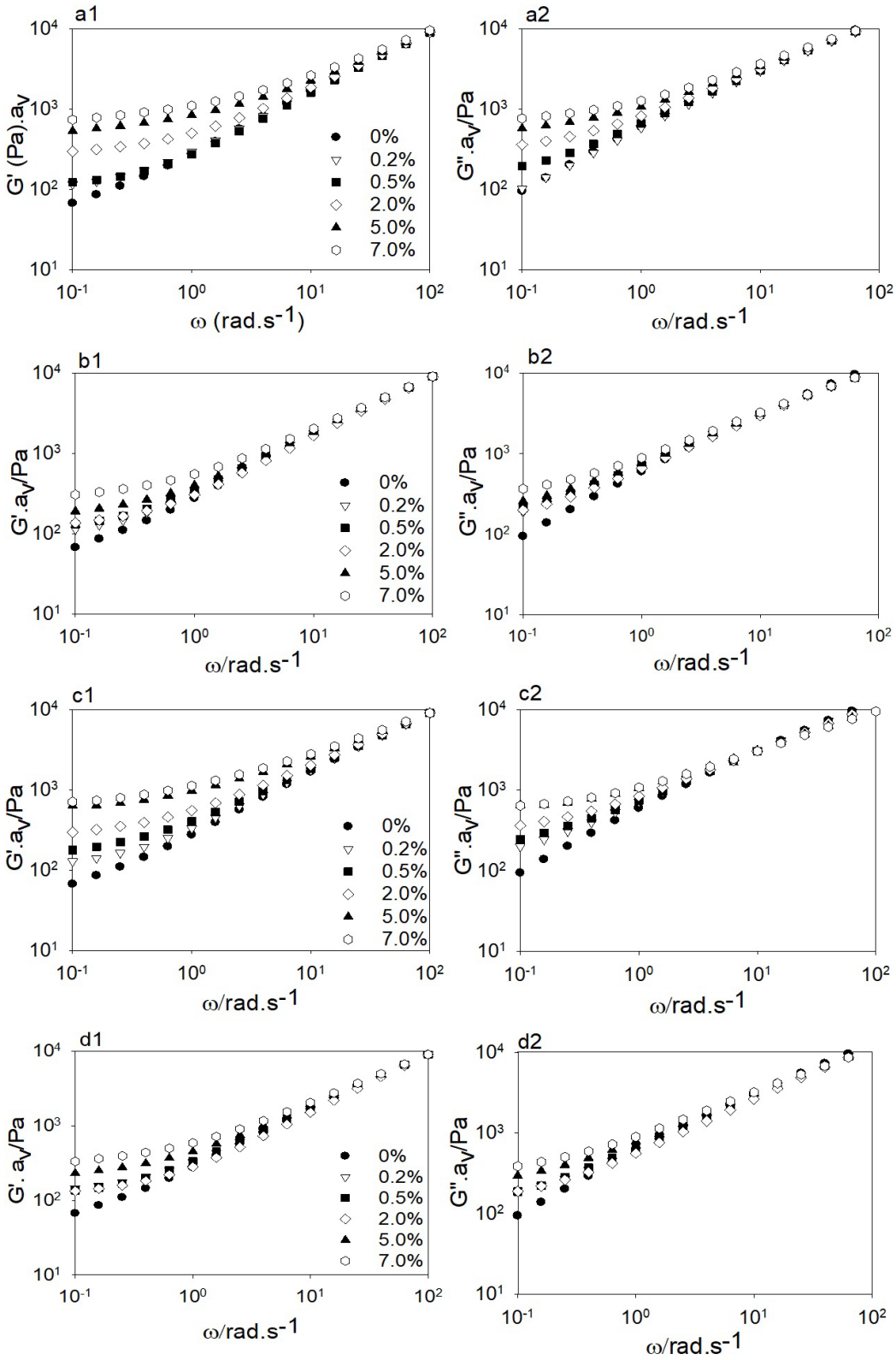

Figure 4. Master curves of the frequency dependence of G' (1) and G" (2) for LDPE filled with Ni/Al-LDH, intercalated with DDS (a1, a2), STE (b1, b2), LAU (c1, c2) and PAL (d1, d2), obtained by the superposition of different LDH loadings, from 0 to $7 \mathrm{wt} \%$. The reference used was neat LDPE. 
Table 1. Neat LDPE and LDPE/LDH thermal properties obtained from DSC curves.

\begin{tabular}{|c|c|c|c|c|c|c|c|c|c|c|}
\hline \multirow{3}{*}{ Sample } & \multicolumn{4}{|c|}{ Melting } & \multicolumn{4}{|c|}{ Crystallization } & \multirow{2}{*}{\multicolumn{2}{|c|}{ Peak ratio }} \\
\hline & \multicolumn{2}{|c|}{$\mathbf{T}_{\mathrm{m}}\left({ }^{\circ} \mathrm{C}\right)$} & \multicolumn{2}{|c|}{$\Delta H_{m}(J / g)$} & \multicolumn{2}{|c|}{$\mathrm{T}_{\mathrm{c}}\left({ }^{\circ} \mathrm{C}\right)$} & \multicolumn{2}{|c|}{$\Delta H_{c}(J / g)$} & & \\
\hline & $\mathrm{T}_{\mathrm{m} 1}\left({ }^{\circ} \mathrm{C}\right)$ & $\mathrm{T}_{\mathrm{m} 2}\left({ }^{\circ} \mathrm{C}\right)$ & $\Delta H_{\mathrm{m} 1}(\mathrm{~J} / \mathrm{g})$ & $\Delta \mathbf{H}_{\mathrm{m} 2}(\mathrm{~J} / \mathrm{g})$ & $\mathrm{T}_{\mathrm{c} 1}\left({ }^{\circ} \mathrm{C}\right)$ & $\mathrm{T}_{\mathrm{c} 2}\left({ }^{\circ} \mathrm{C}\right)$ & $\Delta H_{\mathrm{c} 1}(\mathrm{~J} / \mathrm{g})$ & $\Delta H_{\mathrm{c} 2}(\mathrm{~J} / \mathrm{g})$ & $\mathbf{c 2} / \mathbf{c 1}$ & $\mathrm{m} 2 / \mathrm{m} 1$ \\
\hline Neat LDPE & 105 & - & -88.2 & - & 88 & - & 74.5 & - & - & - \\
\hline $\mathrm{Co} / \mathrm{Al}-\mathrm{STE} 0.2 \%$ & 103 & 128 & -80.8 & -14.7 & 89 & 109 & 50.1 & 14.7 & 0.29 & 0.18 \\
\hline $\mathrm{Co} / \mathrm{Al}-\mathrm{STE} 0.5 \%$ & 103 & 128 & -73.1 & -13.1 & 89 & 108 & 48.1 & 12.7 & 0.26 & 0.18 \\
\hline $\mathrm{Co} / \mathrm{Al}-\mathrm{STE} 7 \%$ & 103 & 128 & -54.6 & -13.6 & 88 & 108 & 48.4 & 14.0 & 0.29 & 0.25 \\
\hline $\mathrm{Co} / \mathrm{Al}-\mathrm{PAL} 0.2 \%$ & 103 & 128 & -81.7 & -18.2 & 88 & 109 & 54.4 & 17.8 & 0.33 & 0.22 \\
\hline $\mathrm{Co} / \mathrm{Al}-\mathrm{PAL} 0.5 \%$ & 103 & 128 & -51.9 & -9.7 & 89 & 107 & 39.6 & 9.80 & 0.25 & 0.19 \\
\hline $\mathrm{Co} / \mathrm{Al}-\mathrm{PAL} 7 \%$ & 104 & 128 & -40.7 & -10.8 & 88 & 107 & 39.5 & 11.5 & 0.29 & 0.27 \\
\hline
\end{tabular}

$\mathrm{m}=$ melting; $\mathrm{c}=$ crystallization; Peak $1=$ low temperature; Peak $2=$ high temperature.

due to the presence of transient networks, usually observed for polymers and characteristic of chain entanglements.

However, for LDPE or LDPE-LDH, no crossing between G' and G' was observed, and G" > G' throughout the frequency sweep, evidencing that in melted state no transient networks were identified for the LDPE at $190^{\circ} \mathrm{C}$. The absence of crossing could reflect the low molar mass of the melted polymers used, and the shift of the crossing between G' and G" to higher frequencies indicated lower relaxation time $(\tau)$ for LDPE at $190{ }^{\circ} \mathrm{C}$.

For the fillers Ni/Al-STE and Ni/Al-PAL, almost the same $a_{v}$ values were observed. Ni/Al-LAU LDPE nanocomposites presented a shift factor higher than the previous two fillers and the most significant $a_{v}$ values were related to $\mathrm{Ni} / \mathrm{Al}$-DDS. The significant reduction of G' and G" due to presence of LDH can be attributed to a phase separation process, as hypothesized above, with polymer concentration reduction in the bulk. Based on the $\mathrm{a}_{\mathrm{v}}$ values calculated at higher frequencies, LDH and LDPE fractions were excluded from the LDPE matrix, and it was found that the phase separation can reduce the concentration of both LDH and LDPE in the bulk.

This LDPE-LDH phase separation was attributed to formation of aggregates that are segregated from the continuous phase of LDPE-LDH nanocomposites. This effect will be better described in SEM and DSC measurements (Figure 1 and 2). Apparently, some regions of LDH interact strongly with the LDPE, but somehow this fraction separates from the continuous phase. Other possibilities are some incompatibility and inducement of crystallization of LDPE. The same aggregation of PE/LDH was demonstrated by Costa et al. ${ }^{[22,23]}$, who reported that the grafting of polyethylene with maleic anhydride, increased the dispersion and rheological performance, mainly due to hydrophilic interactions.

Despite the phase separation observed, the hydrophobic segments of LDH and LDPE also formed permanent networks, from 0.0631 to 5 rad. $\mathrm{s}^{-1}$, since the elastic modulus at low frequencies increased, suggesting the formation of a new network, not observable in the matrix of LDPE, with longer relaxation time. This increase was also observed by Costa et al. ${ }^{[22,23]}$, who attributed it to LDH-LDPE matrix interaction.

In the present case, two different events were observed: one responsible for a significant phase separation process, quantified by $\mathrm{a}_{\mathrm{v}}$, and a permanent network at lower frequencies.
The first one can be attributed to strong hydrophobic interactions between LDPE and LDH, creating nuclei for aggregation, followed by phase separation of the aggregates. Another possibility is some hydrophilic incompatibility between $\mathrm{LDH}$ and matrix, due to lateral zone interactions of the layered crystals and LDPE, promoting phase separation. A final hypothesis investigated by DSC is that LDH induces crystallization of the LDPE, with phase separation (Figure 2).

The permanent network can be associated with interaction of LDPE with the hydrophobic surfaces of LDH, observed as a rise at lower frequencies. This increase was directly related to the new network formed due to association of LDPE-LDH, and it is dependent on filler concentration for Ni/Al-LDH. This network was still present at higher temperatures $\left(190^{\circ} \mathrm{C}\right)$ and can be attributed to the hydrophobic interactions between the LDH and LDPE. A compilation of the vertical shift factors $\left(a_{v}\right)$ used due to Ni/Al-LDH fillers in LDPE is observed in Appendix A (Figure A2).

To complement the permanent network characterization, the complex dynamic viscosity $\left(\eta^{*}\right)$ was calculated, as presented in Equation 4 and Figure 5. The complex viscosity $(\eta *)$ (Figure 5) was calculated from G' and G" after vertical factor $\left(\mathrm{a}_{\mathrm{v}}\right)$ correction, using the following Equations 1 and 2.

$$
\begin{aligned}
& G^{*}=\sqrt{\left(G^{\prime} \cdot a_{v}\right)^{2}+\left(G^{\prime \prime} \cdot a_{v}\right)^{2}} \\
& \eta^{*}=\frac{G^{*}\left(\omega_{i}\right)}{\omega_{i}}
\end{aligned}
$$

where, $G^{*}$ is the complex shear modulus and $\omega_{i}$ is the frequency $i$.

At low frequencies, the rise observed in the calculated $\eta^{*}$ was much more evident in Ni/Al-DDS (Figure 5a) and $\mathrm{Ni} / \mathrm{Al}-\mathrm{LAU}$ (Figure 5c), and the increase of viscosity was much more significant after $\mathrm{a}_{\mathrm{v}}$ correction, demonstrating the formation of a network in LDPE induced by the filler. This up-turn also appeared at higher frequencies with increasing LDH concentration, suggesting that the permanent network started to dominate the bulk phase.

To confirm the permanent network, aggregation and hydrophobic interactions induced by the filler for comparative purpose, another $\mathrm{LDH}(\mathrm{Co} / \mathrm{Al})$, with the same intercalated ions (DDS, LAU, PAL and STE) was used. The G' and G" of Co/Al-LDH with LAU and STE are presented in Figure 6. 

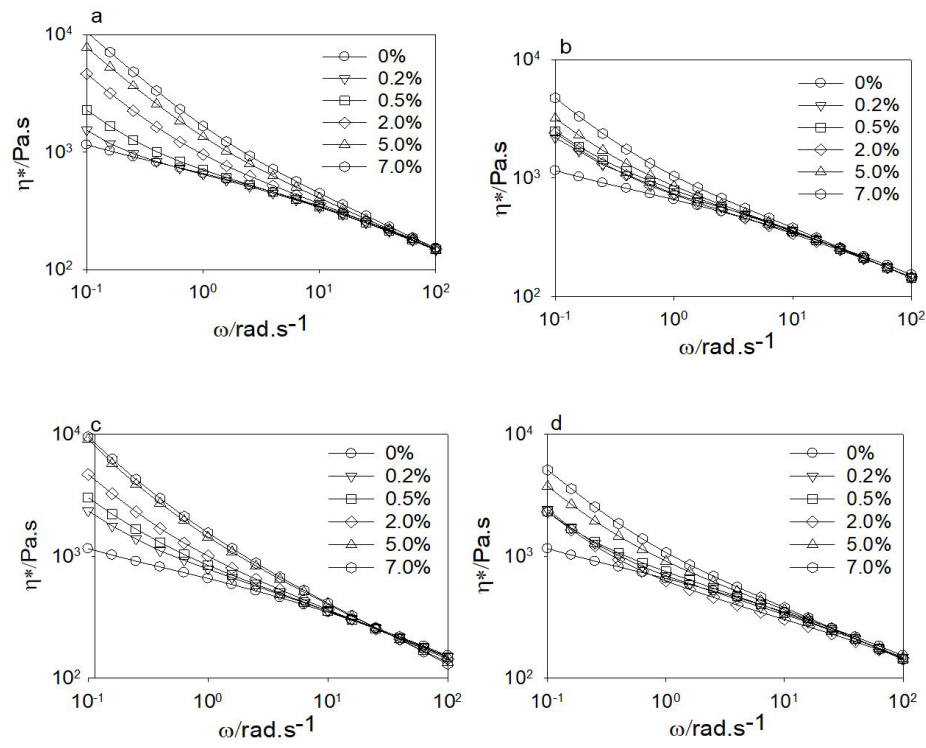

Figure 5. Complex viscosity ( $\left.\eta^{*}\right)$ obtained from G'a and G”' $a_{v}$ for LDPE filled with Ni/Al-LDH, intercalated with DDS (a), STE (b), LAU(c) and PAL (d), obtained by the superposition of different filler concentrations, from 0 to $7 \mathrm{wt} \%$. The reference used was neat LDPE, at $190^{\circ} \mathrm{C}$.
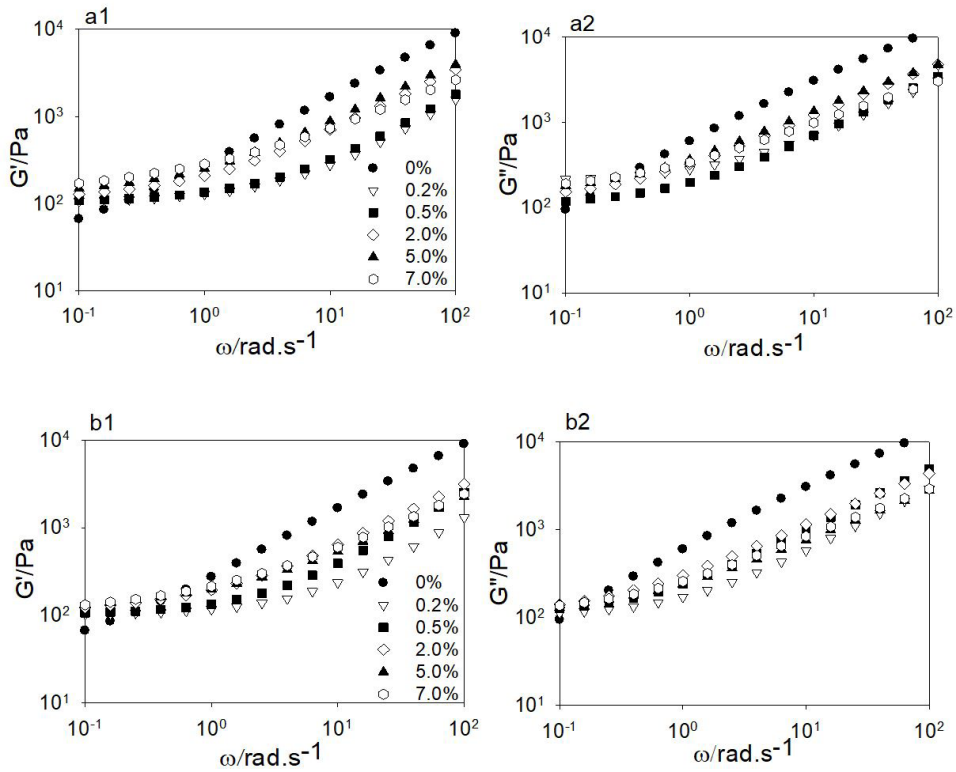

Figure 6. Frequency dependence of the shear moduli G' and G" of Co/Al-LAU (a1 and a2) and Co/Al-STE (b1 and b2) $(0.2,0.5,2.0,5$ and $7 \mathrm{wt} \%)$ in LDPE, at $190{ }^{\circ} \mathrm{C}$.

The shear modulus for Co/Al-LDH DDS and PAL are presented in Appendix A (Figure A3).

Shear moduli reduction was observed for Co/Al-LDH fillers in mixtures with LDPE, compared to Ni/Al-LDH fillers, since in both cases G' and G' moduli of LDPE were smaller. However, the relation was not Co/Al-LDH dependent. All the fillers presented almost the same behavior at high frequencies and high LDH concentration (7 wt \%).
The G' and G" moduli were normalized, for comparative purposes, using $\mathrm{a}_{\mathrm{v}}$ at high frequency $\left(\sim 100 \mathrm{rad}_{\mathrm{s}}{ }^{-1}\right)$ (Figure 7).

For Co/Al-LDH with different intercalated ions, the up-turn at lower frequencies was much more evident than for $\mathrm{Ni} / \mathrm{Al}-\mathrm{LDH}$, even at low $\mathrm{Co} / \mathrm{Al}-\mathrm{LDH}$ concentration (0.2-0.5 wt \%). With relation to aggregates formed, the phase-separation from the continuous phase was much more evident for $\mathrm{Co} / \mathrm{Al}-\mathrm{STE}$, even at the lowest concentration 

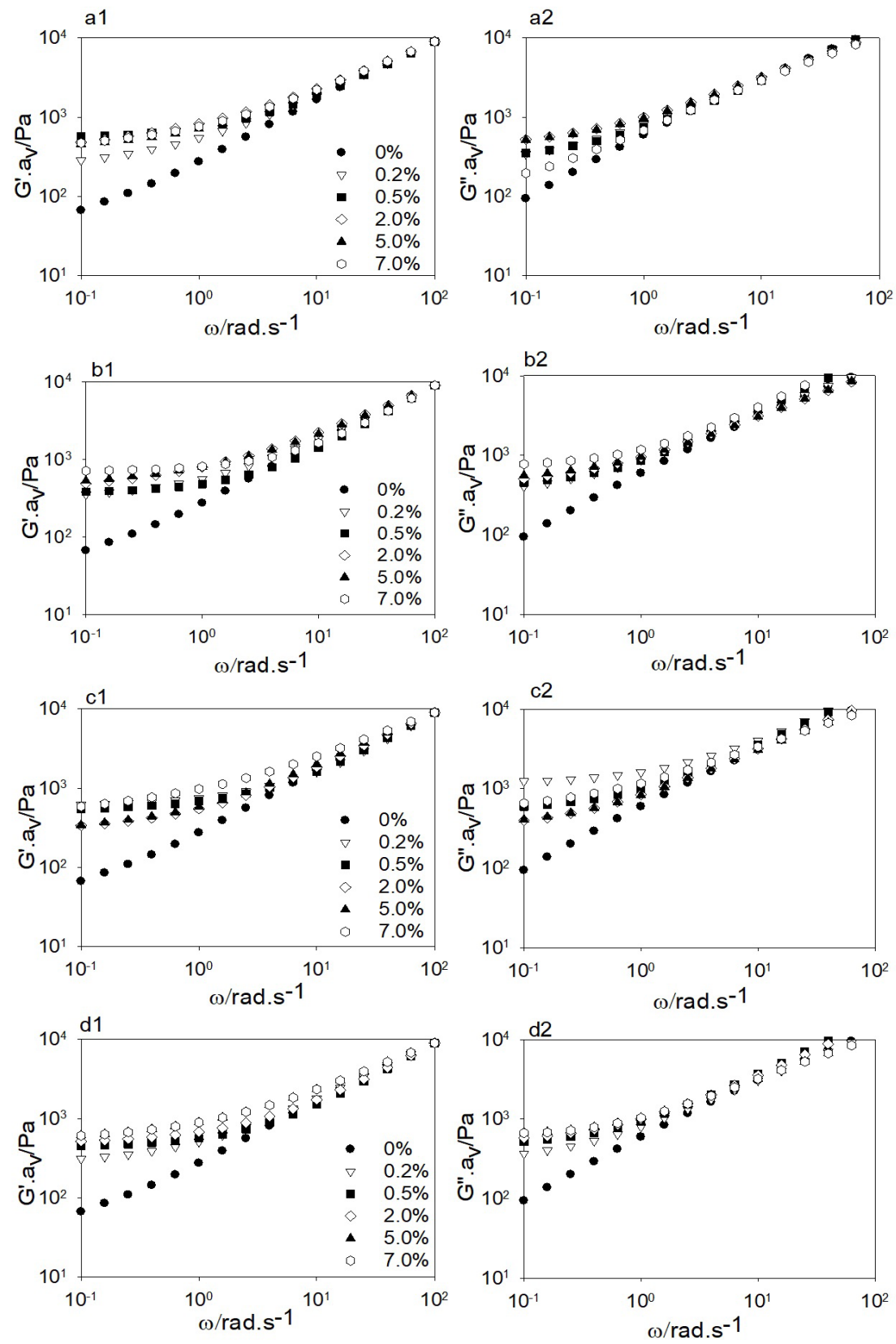

Figure 7. Master curves of the frequency dependence of G' and G' for LDPE filled with Co/Al-LDH, intercalated with ions of DDS (a1, a2), STE (b1, b2), LAU (c1, c2) and PAL (d1, d2), obtained by the superposition of different filler concentrations, from 0 to $7 \%$. The reference used was neat LDPE.

$(0.2 \mathrm{wt} \%)$ (Figure 7). The up-turn observed at low frequency in the samples is consistent with the observation that the sample was delaminated/exfoliated in the polymeric matrix ${ }^{[33]}$.

The higher phase separation of the Co/Al-LDH for the LDPE compared to Ni/Al-LDH was also evident due to lower concentration of LDH, which induced aggregation and shear moduli reduction, clearly observed by the shift-factors (Appendix A, Figure A4). Also, after normalization of G' and G" by $a_{v}$, no evident differences were observed when using a higher concentration of LDH
( $7 \mathrm{wt} \%$ ) at higher frequencies $\left(>10 \mathrm{rad}_{\mathrm{s}} \mathrm{s}^{-1}\right)$, suggesting that most of the LDPE-LDH phase separated, and the G' and G" values of the continuous phase were almost independent of the filler at higher concentration.

In the lower frequency region $\left(0.0631\right.$ to $\left.5 \mathrm{rad}^{-\mathrm{s}^{-1}}\right)$, where the permanent network was observed for LDH and LDPE PNC, the samples with the strongest remaining networks in the continuous phase were $\mathrm{Co} / \mathrm{Al}-\mathrm{LAU}$ and $\mathrm{Co} / \mathrm{Al}-\mathrm{PAL}$ mixtures with LDPE (Figure 8c, d). All the samples at low 

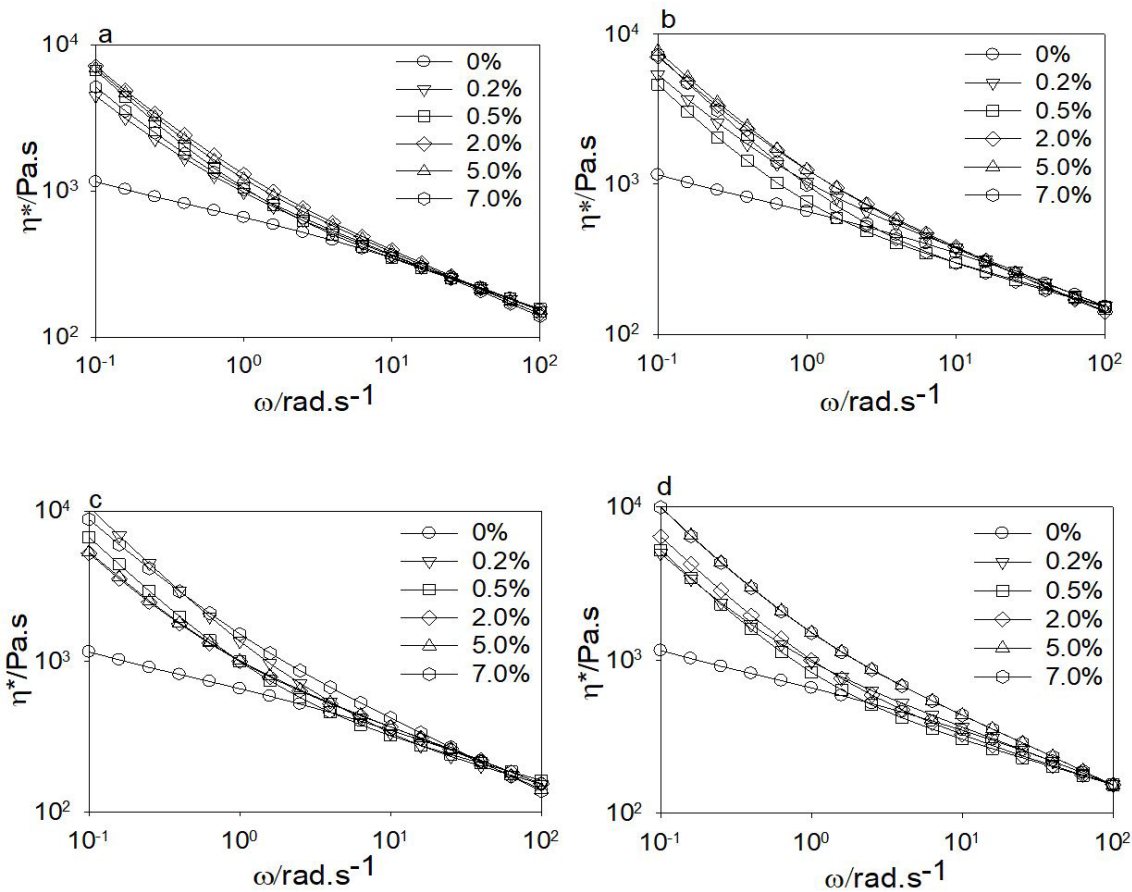

Figure 8. Complex viscosity ( $\left.\eta^{*}\right)$ obtained from G'a and G'a for LDPE filled with Co/Al-LDH, intercalated with DDS (a), STE (b), LAU (c) and PAL (d), obtained by the superposition of different filler concentrations, from 0 to $7 \mathrm{wt} \%$. The reference used was neat LDPE.

concentration presented almost the same shear thinning behavior at very low frequencies, compared to LPDE samples.

The contrast between the SEM images and rheological clearly demonstrate phase separation, it can be a very powerful association technique to indicate LDH and polymer incompatibility and inhomogeneities.

The second event observed by DSC (Figure 2 and Table 1) can be attributed to hydrophobic interaction between $\mathrm{LDH}$ and LDPE also observed by rheology as an up-turn at very low frequency range $\left(0.0631\right.$ to $\left.5 \mathrm{rad} . \mathrm{s}^{-1}\right)$. The phase-separated material was still present in the samples up to $190{ }^{\circ} \mathrm{C}$, the temperature of the rheological analysis, suggesting melting of the aggregates at much higher temperatures. Apparently, the aggregates remaining at higher temperatures promoted some nucleation and LDPE organization, induced probably by hydrophobic interactions.

\section{Conclusions}

Pink cobalt/aluminum and green nickel/aluminum layered double hydroxide (LDH - $\mathrm{M}^{+2}$ : Al molar ratio of 3:1) were successfully intercalated with dodecylsulphate (DDS), laurate (LAU), stearate (STE) and palmitate (PAL) as pure phases. First, the carbonate intercalated phases were obtained by urea hydrolysis, where carbonate was replaced by chloride anions from the acetate/ $\mathrm{NaCl}$ buffer solution, followed by cation exchange reaction with the desired organic anions. After characterization by several instrumental techniques, the nanometric thick layered crystals were used as fillers in low-density polyethylene (LDPE) in percentages between
0.2 and $7 \mathrm{wt} \%$, producing colored polymer nanocomposites by injection molding.

Scanning electron microscopy (SEM) images indicated that most of the samples were poorly dispersed in the polymeric matrix. Thermal behavior analyzed by differential scanning calorimetry (DSC) indicated that in the $\mathrm{Ni} / \mathrm{Al}$ samples, the melting and crystallization were almost unchanged in relation to the neat LDPE, while in the samples Co/Al-PAL and $\mathrm{Co} / \mathrm{Al}-\mathrm{STE}$, a second phase, and to a lesser extent, a third phase were observed, with higher crystallization and melting temperature than in the presence of neat LDPE. This high temperature phase is attributed to the formation of polymer crystals domain induced by the LDH filler particles.

The measured crystallization and melting enthalpies of both Co/Al-LDPE samples declined with increasing filler content, indicating a reduction of the crystallinity indices, caused by the LDH influence. Rheological properties indicated the formation of a permanent network, reducing shear moduli and hindering the filler dispersion, producing agglomerates, especially for the samples Ni/Al-LAU, Ni-Al-DDS, Co/Al-LAU, Ni/Co-PAL.

In fact, as reported previously ${ }^{[33]}$, only samples Ni/Al-STE and $\mathrm{Co} / \mathrm{Al}-\mathrm{STE}$ presented effective delamination/exfoliation.

\section{Acknowledgements}

We thank Conselho Nacional de Desenvolvimento Científico e Tecnológico (CNPq) (Proc. 303846/2014-3), Coordenação de Aperfeiçoamento de Pessoal de Nível Superior (CAPES), Financiadora de Estudos e Projetos (FINEP) and Universidade Federal do Paraná (UFPR) for 
financial support. S.J. also thanks CNPq - Ciências sem Fronteiras for the Ph.D. grant in the Leibniz-Institut für Polymerforschung Dresden, Germany, where part of this work was developed.

\section{References}

1. Jia, C., Qian, Y., Chen, X., \& Liu, Y. (2014). Flame retardant ethylene-vinyl acetate composites based on layered double hydroxides with zinc hydroxystannate. Polymer Engineering and Science, 54(12), 2918-2924. http://dx.doi.org/10.1002/ pen.23849.

2. Peres, A. M., Pires, R. R., \& Oréfice, R. L. (2016). Evaluation of the effect of reprocessing on the structure and properties of low density polyethylene/thermoplastic starch blends. Carbohydrate Polymers, 136(20), 210-215. http://dx.doi. org/10.1016/j.carbpol.2015.09.047. PMid:26572348.

3. Mathioudakis, I. G., Vogiatzis, G. G., Tzoumanekas, G. G., \& Theodorou, D. N. (2016). Molecular modeling and simulation of polymer nanocomposites at multiple length Scales. IEEE Transactions on Nanotechnology, 15(3), 416-422. http://dx.doi. org/10.1109/TNANO.2016.2538460.

4. Peng, D., Wei, C., \& Baojun, Q. (2006). Recent progress in polymer layered double hydroxide nanocomposites. Progress in Natural Science, 16(6), 573-579. http://dx.doi. org/10.1080/10020070612330037.

5. Ding, P., \& Qu, B. (2006). Synthesis of exfoliated PP/LDH nanocomposites via melt-intercalation: structure, thermal properties, and photo-oxidative behavior in comparison with PP/MMT nanocomposites. Polymer Engineering and Science, 46(9), 1153-1159. http://dx.doi.org/10.1002/pen.20568.

6. Jeon, I. Y., \& Baek, J. B. (2010). Nanocomposites derived from polymers and inorganic nanoparticles. Materials, 3(6), 3654-3674. http://dx.doi.org/10.3390/ma3063654.

7. Nogueira, T., Gonçalves, N., Botan, R., Wypych, F., \& Lona, L. (2016). Layered double hydroxides as fillers in poly(l-lactide) nanocomposites, obtained by in situ bulk polymerization. Polímeros: Ciência e Tecnologia, 26(2), 106-114. http://dx.doi. org/10.1590/0104-1428.2282.

8. Tavares, S. R., Wypych, F., \& Leitão, A. A. (2017). DFT study of the intercalation of layered double hydroxides and layered hydroxide salts with dodecylsulfate and dodecylbenzenesulfonate: exfoliation and hydration properties. Applied Clay Science, 143(1), 107-114. http://dx.doi.org/10.1016/j.clay.2017.03.018.

9. Nogueira, T. R., Botan, R., Macedo Neto, J. C., Wypych, F., \& Lona, L. (2013). Effect of layered double hydroxides on the mechanical, thermal, and fire properties of poly(methyl methacrylate) nanocomposites. Advances in Polymer Technology, 32(S1), E660-E674. http://dx.doi.org/10.1002/adv.21309.

10. Jaerger, S., Zimmermann, A., Zawadzki, S. F., Wypych, F., \& Amico, S. C. (2014). Zinc layered hydroxide salts: intercalation and incorporation into low-density polyethylene. Polímeros: Ciência e Tecnologia, 24(6), 673-682. http://dx.doi. org/10.1590/0104-1428.1733.

11. Silva, M. L. N., Marangoni, R., Silva, A. H., Wypych, F., \& Schreiner, W. H. (2013). Poly(vinyl alcohol) composites containing layered hydroxide salts, intercalated with anionic azo dyes (Tropaeolin 0 and Tropaeolin 0). Polímeros: Ciência e Tecnologia, 23(2), 248-256. http://dx.doi.org/10.4322/S010414282013005000026.

12. Pérez, M. R., Pavlovic, I., Barriga, C., Cornejo, J., Hermosin, M. C., \& Ulibarri, M. A. (2006). Uptake of $\mathrm{Cu}^{2+}, \mathrm{Cd}^{2+}$ and $\mathrm{Pb}^{2+}$ on $\mathrm{Zn}-\mathrm{Al}$ layered double hydroxide intercalated with EDTA. Applied Clay Science, 32(3-4), 245-251. http://dx.doi. org/10.1016/j.clay.2006.01.008.
13. Yu, S., Wang, X., Chen, Z., Wang, J., Wang, S., Hayat, T., \& Wang, X. (2016). Layered double hydroxide intercalated with aromatic acid anions for the efficient capture of aniline from aqueous solution. Journal of Hazardous Materials, 32, 111-120. http://dx.doi.org/10.1016/j.jhazmat.2016.09.009. PMid:27614324.

14. Stimpfling, T., Leroux, F., \& Hintze-Bruening, H. (2014). Organo-modified layered double hydroxide in coating formulation to protect AA2024 from corrosion. Colloids and Surfaces. A, Physicochemical and Engineering Aspects, 458, 147-154. http://dx.doi.org/10.1016/j.colsurfa.2014.01.042.

15. Chen, Y., \& Song, Y. F. (2013). Highly selective and efficient removal of $\mathrm{Cr}$ (VI) and $\mathrm{Cu}(\mathrm{II})$ by the chromotropic acidintercalated $\mathrm{Zn}-\mathrm{Al}$ layered double hydroxides. Industrial \& Engineering Chemistry Research, 52(12), 4436-4442. http:// dx.doi.org/10.1021/ie400108t.

16. Lonkar, S. P., Morlat-Therias, S., Caperaa, N., Leroux, F., Gardette, J. L., \& Singh, R. P. (2009). Preparation and nonisothermal crystallization behavior of polypropylene/ layered double hydroxide nanocomposites. Polymer, 50(6), 1505-1515. http://dx.doi.org/10.1016/j.polymer.2009.01.031.

17. Landman, E. P., \& Focke, W. W. (2006). Stearate intercalated layered double hydroxides: effect on the physical properties of dextrin-alginate films. Journal of Materials Science, 41(8), 2271-2279. http://dx.doi.org/10.1007/s10853-006-7173-8.

18. Manzi-Nshuti, C., Songtipya, P., Manias, E., Jimenez-Gasco, M. M., Hossenlopp, J. M., \& Wilkie, C. A. (2009). Polymer nanocomposites using zinc aluminum and magnesium aluminum oleate layered double hydroxides: Effects of LDH divalent metals on dispersion, thermal, mechanical and fire performance in various polymers. Polymer, 50(15), 3564-3574. http://dx.doi.org/10.1016/j.polymer.2009.06.014.

19. Cursino, A. C. T., Lisboa, F. S., Pyrrho, A. S., Souza, V. P., \& Wypych, F. (2013). Layered double hydroxides intercalated with anionic surfactants/benzophenone as potential materials for sunscreens. Journal of Colloid and Interface Science, 397(1), 88-95. http://dx.doi.org/10.1016/j.jcis.2013.01.059. PMid:23481517.

20. Marangoni, R., Bouhent, R., Taviot-Gueho, C., Wypych, F., \& Leroux, F. (2009). Zn Al layered double hydroxides intercalated and adsorbed with anionic blue dyes: a physico-chemical characterization. Journal of Colloid and Interface Science, 333(1), 120-127. http://dx.doi.org/10.1016/j.jcis.2009.02.001. PMid:19249793.

21. Marangoni, R., Mikowski, A., \& Wypych, F. (2010). Effect of adsorbed/intercalated anionic dyes into the mechanical properties of PVA: layered zinc hydroxide nitrate nanocomposites. Journal of Colloid and Interface Science, 351(2), 384-391. http://dx.doi.org/10.1016/j.jcis.2010.08.006. PMid:20804981.

22. Costa, F. R., Wagenknecht, U., Jehnichen, D., Goad, M. A., \& Heinrich, G.. (2006). Nanocomposites based on polyethylene and Mg-Al layered double hydroxide. Part II. Rheological characterization. Polymer, 47(5), 1649-1660. http://dx.doi. org/10.1016/j.polymer.2005.12.011.

23. Costa, F. R., Saphiannikova, M., Wagenknecht, U., \& Heinrich, G. (2007). Layered double hydroxide based polymer nanocomposites. Advances in Polymer Science, 210, 101-168. http://dx.doi.org/10.1007/12_2007_123.

24. Costa, F. R., Abdel-Goad, M., Wagenknecht, U., \& Heinrich, G. (2005). Nanocomposites based on polyethylene and Mg-Al layered double hydroxide. I. Synthesis and characterization. Polymer, 46(12), 4447-4453. http://dx.doi.org/10.1016/j. polymer.2005.02.027.

25. Costa, F. R., Wagenknecht, U., Jehnichen, D., \& Heinrich, G. (2006). Nanocomposites based on polyethylene and Mg-Al layered double hydroxide: characterisation of modified clay, 
morphological and rheological analysis of nanocomposites. Plastics, Rubber and Composites, 35(4), 139-148. http://dx.doi. org/10.1179/174328906X103187.

26. Coiai, S., Scatto, M., Conzatti, L., Azzurri, F., Andreotti, L., Salmini, E., Stagnaro, P., Zanolin, A., Cicogna, F., \& Passaglia, E. (2011). Optimization of organo-layered double hydroxide dispersion in LDPE-based nanocomposites. Polymers for Advanced Technologies, 22(12), 2285-2294. http://dx.doi. org/10.1002/pat.1759.

27. Kutlu, B., Leuteritz, A., Boldt, R., Jehnichen, D., Wagenknecht, U., \& Heinrich, G. (2013). PANI-LDH prepared by polymerizationadsorption method and processing to conductive compounds. Applied Clay Science, 72, 91-95. http://dx.doi.org/10.1016/j. clay.2013.01.002.

28. Gao, Y, Wang, Q., Wang, J. Y., Huang, L., Yan, X. R., Zhang, X., He, Q. L., Xing, Z. P., \& Guo, Z. H. (2014). Synthesis of highly efficient flame retardant high-density polyethylene nanocomposites with inorgano-layered double hydroxides as nanofiller using solvent mixing method. ACS Applied Materials \& Interfaces, 6(7), 5094-5104. http://dx.doi.org/10.1021/ am500265a. PMid:24597470.

29. Solomon, M. J., Almusallam, A. S., Seefeldt, K. F., Somwangthanaroj, A., \& Varadan, P. (2001). Rheology of polypropylene/clay hybrid materials. Macromolecule, 34(6), 1864-1872. http://dx.doi.org/10.1021/ma001122e.

30. Lonkar, S. P., Therias, S., Leroux, F., Gardette, J. L., \& Singh, R. P. (2012). Thermal, mechanical, and rheological characterization of polypropylene/layered double hydroxide nanocomposites. Polymer Engineering and Science, 52(9), 2006-2014. http://dx.doi.org/10.1002/pen.23147.

31. Zaman, H. U., \& Beg, M. D. H. (2014). Influence of two novel compatibilizers on the properties of LDPE/organoclay nanocomposites. Journal of Polymer Engineering, 34(1), 1-9. http://dx.doi.org/10.1515/polyeng-2013-0144.

32. Lee, Y., \& Porter, R. S. (1987). Double-melting behavior of poly(ether ether ketone). Macromolecule, 20(6), 1336-1341. http://dx.doi.org/10.1021/ma00172a028.

33. Jaerger, S., Zawadzki, S. F., Leuteritz, A., \& Wypych, F. (2017). J. New alternative to produce colored polymer nanocomposites: organophilic $\mathrm{Ni} / \mathrm{Al}$ and $\mathrm{Co} / \mathrm{Al}$ layered double hydroxide as fillers into low-density polyethylene. Journal of the Brazilian Chemical Society. http://dx.doi.org/10.21577/0103-5053.20170093.

Received: Sept. 20, 2017

Revised: July 23, 2018

Accepted: Sept. 06, 2018 
Appendix A. Rheology of LDPE filled with Ni/Al-LDH or Co/Al-LDH intercalated with DDS or PAL and the shift factors $\left(\mathrm{a}_{\mathrm{v}}\right)$ used in the master curves.
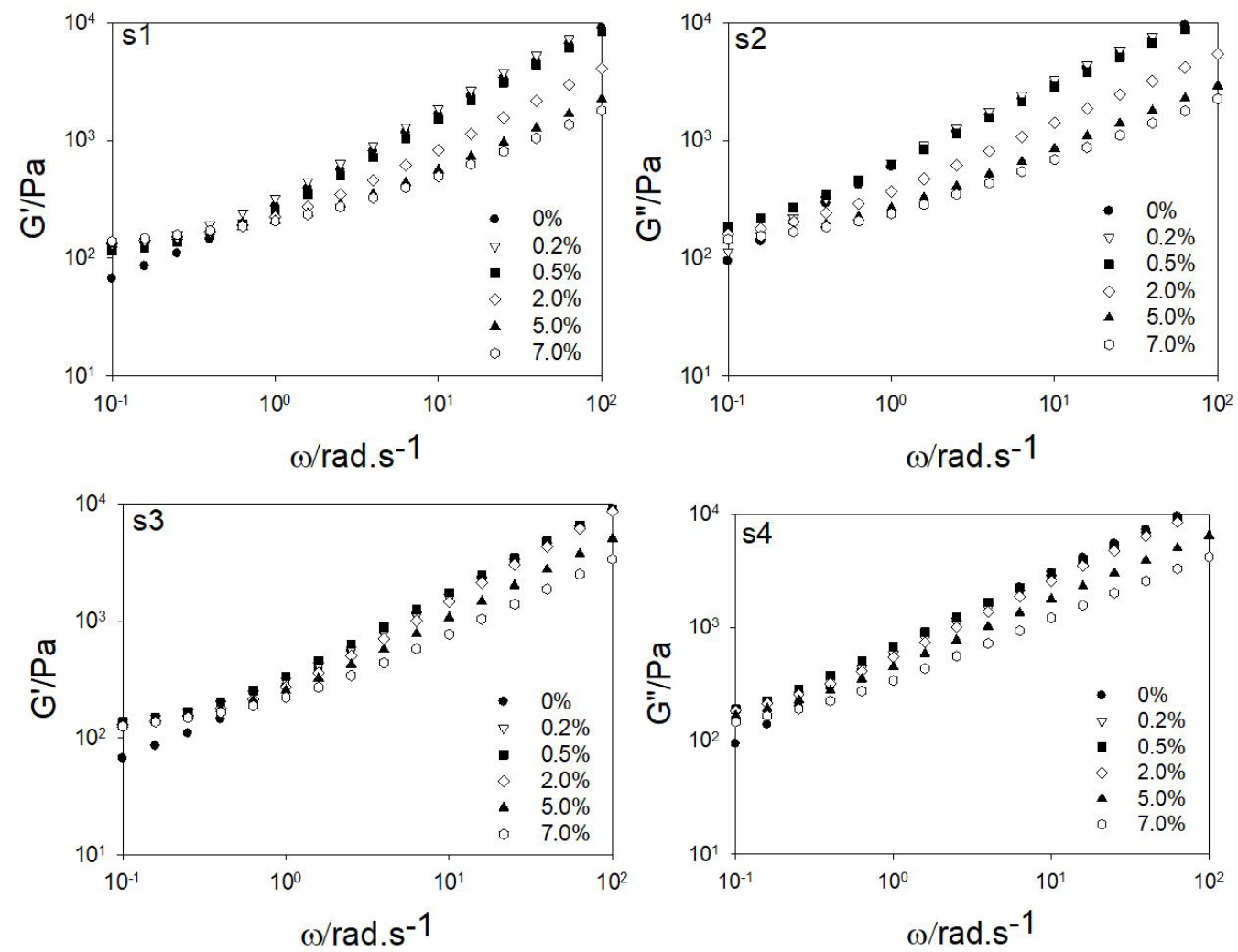

Figure A1. Master curves of the frequency dependence of G' (S1, S3) and G" (S2, S4) of LDPE filled with Ni/Al-LDH, intercalated with ions of DDS (S1, S2) and PAL (S3, S4), obtained by the superposition of different filler concentrations, from 0 to $7 \mathrm{wt} \%$. The reference used was neat LDPE.

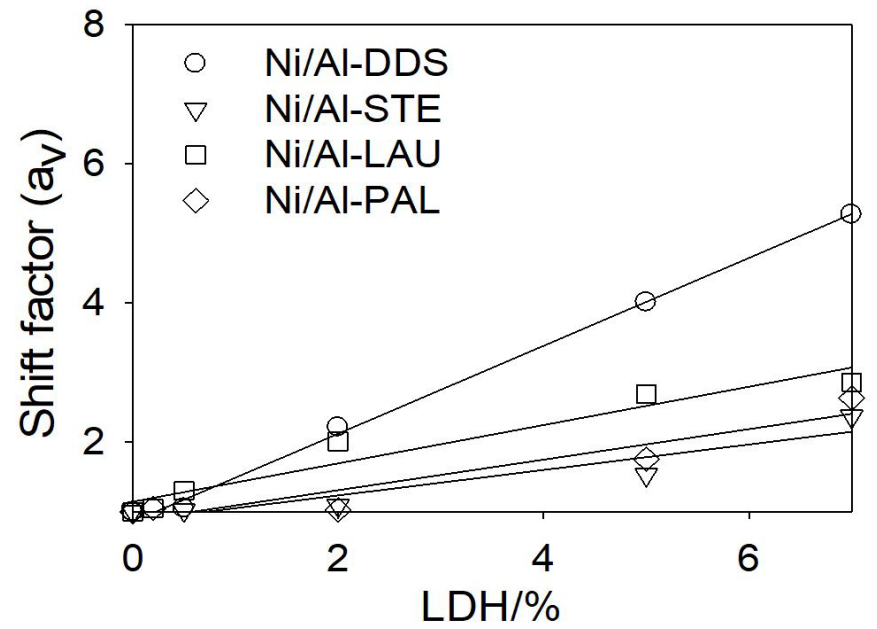

Figure A2. Vertical Shift factors $\left(a_{v}\right)$ used due to Ni/Al-LDH fillers in LDPE. The a values were calculated based on the shear modulus G' of LDPE at $190^{\circ} \mathrm{C}$. 

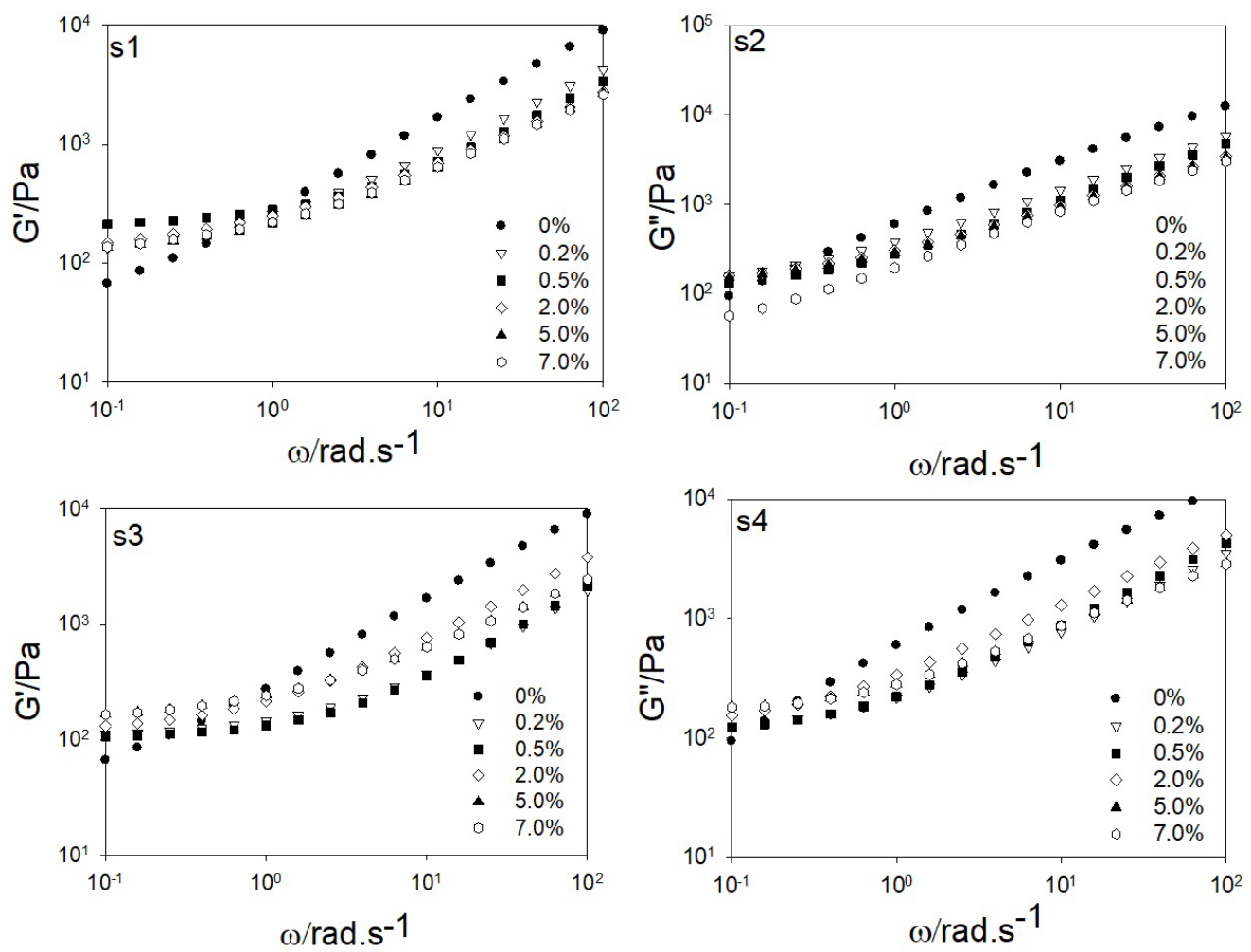

Figure A3. Master curves of the frequency dependence of G' (S1, S3) and G" (S2, S4) of LDPE filled with Co/Al-LDH, intercalated with ions of DDS (S1, S2) and PAL (S3, S4), obtained by the superposition of different filler concentrations, from 0 to $7 \mathrm{wt} \%$. The reference used was neat LDPE.

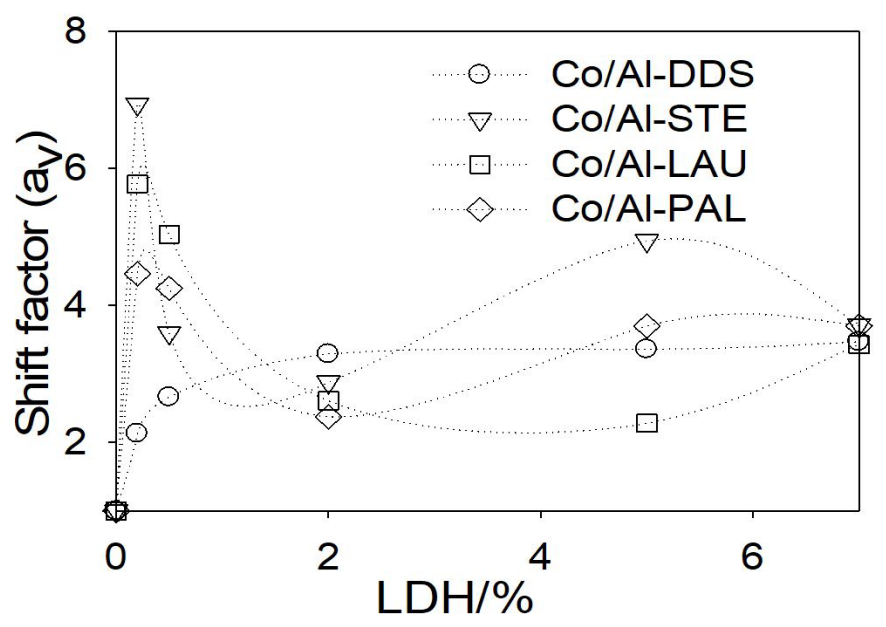

Figure A4. Vertical shift factors $\left(\mathrm{a}_{\mathrm{v}}\right)$ used due to Co/Al-LDH fillers in LDPE. The $\mathrm{a}_{\mathrm{v}}$ values were calculated based on LDPE at $190{ }^{\circ} \mathrm{C}$. 